NBER WORKING PAPER SERIES

TESTING THE SORTING MDDEL OF EDUCATION

Andrew Weiss

Working Paper No. 1420

NATIONAL BUREAU OF ECONOMIC RESEARCH

1050 Massachusetts Avenue

Cambridge, MA 02138

August 1984

The research reported here is part of the NBER's research program in Labor Studies and project in Productivity (World Economy). Any opinions expressed are those of the author and not those of the National Bureau of Economic Research. 
NBER Working Paper \#1420 August 1984

Testing the Sorting Model of Education

$\underline{\text { ABSTRACT }}$

Proprietary data for production workers is analyzed to determine which aspects of productivity are affected by secondary schooling. The measures of productivity explored are: propensity to quit and be absent, phosical output per hour, and ability to perform complex tasks. The data suggests that the sorting effect of education is an important determinant of earnings for semi-skilled production workers.

Andrew Weiss

Department of Economics

Columbia University

New York, NY 10027 


\title{
TESTING THE SORTING MODEL OF EDUCATION'1
}

\author{
Andren Weiss \\ Columbia University \\ New York, N.Y. 10027 \\ and \\ Bell Communications Research
}

Revised July 16, 1984

It is well known that better educated workers earn more. It is not well known why. Are they paid more because of cognitive skills that are learned in school? Because of affective skills that are learned? Or because of traits that are positively correlated with length of schooling but are not learned during the years in which schooling differences occur? This paper provides some tentative answers to those questions. We investigate various aspects of the performance of production workers to see if those aspects of performance that are positively correlated with education are ones that were likely to have been learned during the additional years of schooling acquired by the better educated workers in our sample; and which years were most important for the traits or skills measured by the relevant performance criterion. In particular, we investigate whether

1. I am grateful to Roger Klein, Richard Spady, and participants at the Labor Economics seminars at the University of Chicago and Columbia University, for valuable comments and suggestions. Gerald McTigue. Ali Mouzami and Andrea Shepard provided valuable assistance in processing the data ano in computer programming. John Raisian reconstructed his blue collar-white collar classification scheme for us. 
better educated workers have a comparative advantage on more complex tasks: whether the output per hour of better educated workers is higher than that of less well educated workers: and whether better educated workers have a lower propensity to be absent or to quit. We also investigate whether the relationship between each of these aspects of performance is continuous or whether there is a discrete change associated with high school graduation. Our a priori presumption is that traits such as a low propensity to be absent or to quit are likely to have been learned prior to attendance in secondary school (the overwhelming majority of workers in our sample had between 10 and 14 years of education). Therefore, if the most significant aspect of performance differences for our sample is attendance or quit propensity we would argue that the evidence supports a sorting explanation for the correlation between earnings and education. Of course, one could argue that "persistence". the trait which affects absenteeism and quit propensity is learned in secondary school. To allow for this possibility we let high school graduation to have a discontinuous effect on an individual's probability of quitting his job or being absent. A discontinuous effect of high school graduation is not necessary for confirmation of a sorting model but it is consistent with a particular sorting equilibrium: a mix of pooling and separating contracts (see Weiss [1983. pp. 433]). On the other hand, the existence of pooling Nash equilibria at 12 years of schooling, and the concomitant discontinuous jump in performance at that schooling level, is inconsistent with the usual continuity assumptions made in human capital theoretic models. We also used the PSID sample to investigate whether the return to high school graduation is greater during business beoms or slumps. Presumably a low propensity to quit is less valued when unemployment is high and firms are laying off workers.

We find that for high school graduation has a strong negative effect on absenteeism and quit propensity. We also find that high school graduation has a large effect on the wages 
of individuals even if education, education squared and education cubed are asso included as right hand variables in an earnings equation. This effect of graduating high school on hourly earnings is counter cyclical; so that in periods and areas where unemployment is high employers pay a smaller premium to high school graduate. Indeed we estimate that a $12 \%$ county unemployment rate completely eliminates the discontinuity in the wage schedule at completion of $12^{\text {th }}$ grade. $^{23}$

In our conversations with personnel officers, a low proportion of leavers within their first six months and a low rate of absenteeism were invariably named as the two most important factors used to evaluate the quality of a cohort of workers. A low quit rate. and low absenteeism. may have a particularly strong effect on the productivity of production workers. In manufacturing, production typically proceeds in series; in the $\mathbf{2 0}$ odd plants we ve visited the output of one worker is an input for another, and there are seidom more than three workers doing any one job. Thus. when a new worker is being trained or a

2. P. H. Mirves and E. E. Lawiler calculated that the total cost of turnover of a bank teller was 85 times as large as his daily earnings plus benefits. Hence, if graduation from H.S. decreases a workers probability of quitting during their first year on the job by $10 \%$, and assuming the average work year was 240 days. H.S. graduation would increase earnings of newly hired bank tellers by $3.5 \%$.

3. Mirves and Lawler also estimated that the total cost of absenteeism for a sample of 160 bank tellers was more than twice the cost in salaries and benefits. Thus if, as we estimate, H.S. graduation results in a 14\% decrease in the percentage of days absent. then we would expect the negative correlation between absenteeism and education to lead to a $2 \%$ higher wage for H.S. graduates working as bank teliers.

Allen (1981) used the 1972-73 Quality of Employment Survey to calculate the effect of wages on absenteeism. He found that the elasticity of the absence rate with respect to marginal wape rate varies from -.35 to -.48 . Since these elasticities stem from partial derivatives we can not directly impute the elasticity of wages with respect to absenteeism from the inverse of Allen's estimates. However his results suggesı that if, as we estimate, high school graduates are absent $14 \%$ less than we would expet from their other demographic characteristics, then these difference in absenteeism could explain the entire wage premium received by high school graduates. On the other hand, for all the usual reasons Alles's estimates are likely to be biased toward zero, leading to overestimates of the effect of absenteeism on wages.

Allen also finds a negative, albeit minor, effect of high school graduation on absenteeism. Hewever, since he included wages as an independent variable in his absentecism equation, the model being estimated is subsıanially different from ours-in which we are investigating the effect of education on wages. Consequently if better educated people are paid more because they are absenı less, it might appear that once the researcher controlled for wages there was no statistically significant correlation between education and absenteeism. 
substitute used for an absent worker, the low output of the inexperienced worker affects the output of other workers who must wait for parts. Because of the layout of the plants used in this study and the complementarity between workers and machines, it is seldom possible to avoid disruptions in the production process by temporarily replacing a trained worker who leaves or is absent with several less experienced workers. Frequent changes in the product mix generally make it too cosily to accumulate enough inventory to fully cushion the firm from the effect of quits or absenteeism.

\section{THE DATA}

In order to estimate the relative importance of sorting and learning effects of education. we assembled a data base of 2,920 newly hired semi-skilled production workers employed by the same firm at three widely separated geographic locations. Each of these workers was initially paid the same non-linear piece-rate. When a worker achieves $83 \%$ of expected output for one month, the worker is assigned to a pay group. All the members of a pay group receive the same pay. This pay is proportional to the output of the group - the average group size is 126 members - and promotion opportunities are insignificant. so there is little financial incentive for group members to achieve at high levels of output. Consequently, we only used the output of workers during their first month on the job in this study:

Because almost all workers were assigned to a pay group within their first three months on the job, and the lower bound on earnings of newly hired workers was $65 \%$ of the wage in a pay group, with earnings rising less than proportionately to output up to a ceiling at $83 \%$ of the pay group wage, annual earnings differences among the newly hired workers at each location were trivial. Therefore, in the data analysis described below we did not compute these minor pay differences among workers. 
Previous studies of quit behavior, absenteeism or productivity that used samples of workers with very different pay typically included wages as independent variables. Those studies suffer from simultaneous equation bias. If employers value a low propensity to be absent or to quit or a high level of productivity, then workers who have those qualities (or are perceived by employers as more likely to have those qualities) will receive higher wages and more training. Hence the error term in the quit, absenteeism, and productivity equations is correlated with the wage variable and hence with all other independent variables that are correlated with wages. Although all the workers at each location in our sample received the same wage, they obviously did not have the same alternative opportunities, the effect of differences in alternative opportunities is discussed below.

The data base we assembled is also unique in providing a large and detailed sample of workers on very similar jobs with almost identical wage profiles on those jobs. Hence we are able to separate the effects of jobs on quits and absenteeism from the effects of personspecific variables. That is, for a sample of workers on a wide variety of different jobs a reported low quit propensity of better educated workers could be due to steep wage tenure profiles on the jobs they take. In our data set this problem does not arise since all workers face the same wage-tenure profiles and promotion opportunities (nill).

For each worker data were available on sex, age, marital status, education, employment status when the worker applied for work, and the complexity of the assigned job. ${ }^{4}$ as well as output per hour (measured in physical units and normalized by the industrial engineering force to be equivalent across jobs), number of days absent, number of

4. The industrial engineering stafi measured the amount of time required for the average newly hired worker 10 learn each job. This formula heavily weights the number of times per week an experienced operator would perform the talk. We used the logarithm of required training as our estimate of job complexity. 
occasions absent, ${ }^{5}$ whether or not the worker quit and the date. The workers did not know that they were the subjects of an empirical study. All the data were routinely collected either by the personnel office, industrial engineers, or foremen at the three locations. Although the total sample contained 2,920 individuals, complete data were not available for all workers. In some cases workers may have been assigned to jobs for which there were no measures of job complexity, in other cases the worker failed to answer all the questions on the application form. Also at each location different information was available on the personnel records. In the southwest location, race data was not available and only the screw's half of the Crawford Physical Dexterity Test was administered; in the other two locations both the pins and screws sections of the dexterity test were administered before a worker was hired. ${ }^{6}$ The scores on this test were used by the firm in deciding whether to hire the worker, but were not used in assigning workers to jobs. Job assignments were random.

An additional problem arose at the southwest location: the plant was divided into two halves, with significantly different promotional opportunities. Unfortunately the data did not reveal to which half of the plant particular workers were assigned, that initial assignment may not have been random. At that plant, workers assigned to more complex jobs had better promotional opportunities. Because of these unobserved differences in promotion opportunities, the relatively small sample size at location $C$, and the missing data on race, prior experience, employment status when they applied for this job, and scores on the pins section of the dexterity test, we did not use data from the southwest

5. Consecutive days absent are recorded as a single occasion of absentecism.

6. The Crawford Physical Dexterity Test is a two-part test. In the first part an individual uses a tweezers to place pins into sleeves in a pegboard. In the second part small screws are screwed int? sleeves in the pegboard. Each part of the test takes three minutes and the number of operations performed in that time is tabulated. 
location in estimating the quit equations below.

Table 1 presents some summary statistics which provide a context within which to evaluate the data. NA denotes data that were not available.

\section{Insert Table 1 about here}

Because this data set contains direct measures of three aspects of productivity: output per hour, absenteeism (both percentage of days absent and occasions absent), and quit propensity, it is possible to separately measure the effects of education for each of those aspects of productivity. In addition. because the data includes a measure of the complexity of the job to which the worker was assigned, one can estimate whether better educated workers have a comparative advantage on more complex jobs.

Previous economic studies of the effect of education on labor productivity have not differentiated among the various components of productivity: either wages were used as proxies for productivity, or supervisor evaluations were taken to represent productivity (see Medoff and Abraham [1980]). Each of those approaches has been criticized: the former for assuming that wages are proportional to marginal products; ${ }^{7}$ the latter for treating subjective supervisor evaluations as objective measures of productivity. Studies that rely on productivity measures of experienced workers within a given job classification are also subject to important sample selection biases. For example, suppose that education has a positive effect on performance within a given job, and that, as Medoff and Abraham find,

7. Studies that treat wages as equal to marginal products ignore the incentive. sorting and risk sbaring effects of wages that would cause the ratio of wages to productivity to vary systematically with either experience or education. See, for example Salop [1974]. Salop and Salop [1976]. Lazear [1981]. Calvo [1979], Stiglitz [1974]. Calvo and Wellis? [1979]. Weiss [1980]. Guasch and Weiss [1980. 1982] Freeman [1977] and Harris and Holmstrom [1 982]. 
education (and performance) have positive effects on a worker's probability of being promoted. Then among workers within a job classification, (i.e., workers who have not been promoted) education could be negatively correlated with performance even though education increases the performance of workers on the job. ${ }^{8}$ These effects can be seen in Figure 1. The downward sloping line is the criterion for promotion from job 1 to job 2 . If the distribution of perceived productivities w'ere the same at all education levels. and were a symmetric increasing hazard rate distribution, such as the normal or uniform, then on both jobs the better educated workers would be perceived as being less able. ${ }^{9}$ This problem does not arise for our data since none of the workers were promoted during the sample period. ${ }^{10}$ (Note that this sample selection bias does not affect the substantive point made by Medoff and Abraham that within a sample of workers on the same job wages rise with experience despite productivities falling with experience. We are simply pointing out that in jobs in which there are significant promotional opportunities it is difficult to infer the direct effect of experience or education on productivity.)

Insert Figure 1 about here

Before showing how the data provides information on the relative contributions of the sorling and learning aspects of education to earnings, we first examine the effect of

8. Note that the same arguments could be made to explain why Medoff and Abraham find that more experienced workers get worse supervisor recommendations. In most firms seniority. education and

9. An increasing hazard rate distribution is characterized by $\frac{d}{d x}\left\{\frac{f(x)}{1-F(x)}\right\}>0$, where $F(x)$ is the distribution of productivity and $f(x)$ is the density.

10. Another potential problem with using subjective evaluations is that supervisors might measure performance relative to expectations rather than relative to some absolute level as called for by the questionnaire. However. Medoff and Abraham present evidence that these subjective evaluations are not important sources of bias. 
education on earnings for some of the workers in our sample. and discuss whether conclusions drawn from this subsample are applicable to a broader population.

At the midwest location job applicants were asked their wage at their most recent job and whether or not they were currently employed at that job. Using that data, we estimated the effect of an additional year of education on the earnings of those workers who were employed when they applied for their current job. ${ }^{11 .} 12$ Earnings on the previous job were used since for all workers at each plant monetary value of the job per hour worked was approximately the same. Column 3 of Table 2, contains estimates of the effect of various demographic variables on the logarithm of the previous hourly wage of workers at that plant. Columns 1 and 2 reproduce the coefficients estimated by Wesley Mellow using the 1979 current population survey.

Insert Table 2 about here

Table 2 can be used in various ways depending on how ambitious we wish to be. First, the estimates of $\frac{\partial \text { ln wage }}{\partial \text { educ }}$ provide a measure of the effect of education on the earnings (in their previous job) for the subsample of workers for whom we have earnings data. We used that estimate as a standard, and then calculated how much of that effect can be explained by the partial correlation between education and various aspects of performance for workers in that limited sample. This approach does not make any assumptions about

11. We excluded unemployed workers from the sample since the wage on their previous job. one which they either couldn't keep or chose to leave, does not seem representative of their expected earnings. In each case wages at the previous job were used since wages for experienced workers on their current job are a function solely of seniority and the output of the relevant pay group.

12. Obviously this is a biased estimate of the effect of education on earnings for workers in the population the workers in our sample chose to leave the jobs for which we have recorded their exirnings. In section 3 we analyze the direction of this bias. 
the sample being representative of any larger population, avoiding issues of sample selection bias, but simply seeks to find those factors that contributed to earnings differences on previous jobs for workers within this subsample. We assume that performance on current jobs is correlated with previous employers' perceptions of expected performance, e.g. characteristics that are correlated with a low quit propensity may have been rewarded on the previous job even if realized tenure on that job was low. A cautious generalization is to assume that workers for whom usable pay data was available are representative of workers in the sample so that a year of education has approximately a $4 \%$ effect on the hourly wage on other jobs for the workers in this sample. ${ }^{13}$

A second use of the data in Table 2 is to provide a partial check of the importance of sample selection bias for our sample, if one wishes to generalize our results outside our sample. As Heckman has show'n, sample selection bias can have major consequences for the analysis of micro-economic data (see Heckman [1979]). Since our major concern is in explaining the positive correlation between education and earnings. it is useful to check to see if the return of education in our sample is biased. This is a potentially serious problem because one would expect that better educated individuals who apply for these jobs are less representative of their schooling cohort than are less well educated workers. However, the estimated value of the return on education for workers for whom we had wage data is roughly the same as returns estimated using the C.P.S. sample. Thus it does not seem that our sample differs from the CPS sample in ways that grossly distort the effect of education on earnings. In addition, the sign of the effect of race, sex, education, tenure, and experience on the logarithm of the wage is the same for our sample as for the randomly

13. We had usable data on previous pay for $77 \%$ of the workers employed al the midwest focalion (those workers comprised $43 \%$ of the entire sample). 
selected CPS sample.

The personnel practices at these plants also provide grounds for believing that our sample is representative. Only $22 \%$ of applicants whose applications were revieued were rejected. Of those, $85 \%$ were rejected because of a low score on the Crawford Physical Dexterity Test. The estimation procedures included the worker's score on the dexterity test as an independent variable, thus eliminating that potential source of sample selection bias. In addition, the average pay increase for workers for whom we had wage data was $103 \%$, and w'orkers waited more than 36 hours in freezing temperatures to receive job application forms. This evidence indicates that the firm was paying above market wages, reducing the sample selection problems derived from more "able" applicants not applying to the firm, where ability refers to unobserved worker characteristics that are correlated both with observed characteristics and with productivity. ${ }^{14}$ These high wages and the concomitant excess supply of job applicants were routine features at the manufacturing locations of this unionized firm. At another location of this firm recall notices were recently mailed to former employees: $90 \%$ of those who had found alternative work quit their jobs to return to work for the firm. Consequently we have assumed that sample selection biases were small and have not corrected for them. Alternatively we could have used the Bloom and Killingsworth B-K procedure to correct for sample selection bias. (Because the characteristics of excluded observations are unknown the standard Heckit correction can't be used.) However, the B-K procedure is extremely sensitive to assumptions about the distribution of the error term in the selection equation. ${ }^{15}$ Indeed, as they point out, the

14. Of course some residual sample selection bias occurs if unobserved attributes that lead workers 10 wait on line longer. such as the ability 10 withstand the cold. are correlated with both performance measures and with observed attributes we are studying. At the miduest location we know the individual's place on line. That number was uncorrelaled with any of our measures of performance. Consequently, we have assumed that this source of bias is small and have disregarded it.

15. See Olsen (1982) and Muthén and Jöreskog (1983). 
equation being estimated is only identified if the assumed distribution of the error term of the selection equation is nonlinear.

\section{MODELS}

Typically an individual's choice of a level of secondary education is a function of both observable and unobservable traits. The traits that are observable for our sample. and that affect the schooling decision, include age, race, sex and manual dexterity. We grouped together under the rubric "stick-to-itiveness" all the unobserved attributes that affect an individual's choice of a level of schooling. Stick-to-itiveness represents the combined effect on schooling level of characteristics such as a low time discount rate, self-discipline, desire for variety, and susceptibility to illness or to the urge to "take a day off." Years of schooling. and high school graduation are used as proxies for the traits referred to as stick-to-itiveness.

In addition to representing these unobserved characteristics, education also indicates a level of training. We would expect that one skill that is acquired in school is the ability to learn complex tasks. Of course, that skill may have been acquired prior to the years of schooling across which our sample differs (almost the entire sample had at least nine years of education) and influenced the individual's choice of a level of education. Since we intend to show the importance of the sorting effects of education, we assume that skills such as ability to learn complex tasks that affect the productivity of workers and that may plausibly have been learned in secondary school were learned there. That is, we intentionally bias our analysis against a sorting explanation of the effect of education on earnings.

The performance equations we estimate are: whether or not the worker quil during his first six months on the job, absenteeism (both days absent and occasions of absenteeism), 
and output per hour during the first month on the job as a fraction of his expected output given the complexity of the job. (These normalizations are routinely performed by the industrial engineering staff as part of their efforts to compute the piece-rate for different jobs.) The critical independent variables for the analysis are years of education, H.S. graduation. job complexity, and a measure of the "match" between education level and job complexity.

$$
\begin{aligned}
\text { Match } \equiv & {[\text { education }- \text { mean }(\text { education })] \text { times } } \\
& {[\text { job complexity }- \text { mean }(\text { job complexity) }] .}
\end{aligned}
$$

Job complexity was computed by taking the logarithm of the number of weeks the plant's industrial engineering staff estimates it should take a neu employee to learn the job (achie's the average productivity rating for the factory on that job). The main component in the industrial engineers calculation is the number of tinies per week an experienced worker performs the task.

In general we would expect stick-to-itiveness (those unobservable traits which lead individuals to choose higher levels of schooling) to have its greatest effect on quit propensities and to have a lesser effect on other aspects of behavior such as absenteeism. On the other hand, one direct effect of education is to improve alternative opportunities, increasing the probability of a quit.

\subsection{The Quit Model}

Let $\bar{S}_{i}$ denote worker $i$ 's present value of his current job, $\bar{V}_{i}$ denote $i$ 's present value of his best opportunity elsewhere, and $M_{i}$ denote $i$ 's mobility costs (both real and psychic) of a job change (housework and leisure are counted as jobs). Assume worker $i$ is risk neutral and quits if and only if

$$
\bar{V}_{i}-\bar{S}_{i}>M_{i}
$$


To further specify (1). denote the time discount rate of workers by $r$, worker $i$ s age at the start of the observation period by $a_{i}$ and the value of an individual's altemative and present job at time $t$ by $V_{i}(t)$ and $S_{i}(t)$ respectively. Then, assuming maie workers anticipate working until they are 65 years old, and normalizing $t=0$ for the time during which the quit decision is made

$$
\bar{V}_{i}-\bar{S}_{i}=\int_{0}^{65-a_{1}+\dot{\beta} F} e^{-r t}\left[V_{i}(t)-S_{i}(t)\right] d t .
$$

where $F$ is a dummy variable indicating whether a worker is a female, and $\hat{\beta}$ is an estimated parameter of the problem. If females anticipate working fewer years. we would estimate $\hat{\beta}<0$. Next, let $p_{i}(t)$ represent the probability individual $i$ changes jots after the observation period and before period $t$, and let the value of that job change be a weighted average of the value of the previous job and some constant term $B_{1}$,

Assume that the values of the alternative and the present job grow at an exponential rate so that

$$
\begin{aligned}
& V_{i}(t)=e^{u t}\left[\left[1-p_{i}(t)\right] V_{i}(0)+p_{i}(t)\left(\gamma V_{i}(0)+(1-\gamma) B_{i}(0)\right)\right. \\
& S_{i}(t)=e^{u t}\left[1-p_{i}(t) S_{i}(0)+p_{i}(t)\left(\gamma S_{i}(0)+(1-\gamma) B_{i}(0)\right)\right.
\end{aligned}
$$

where $0<\gamma<1$. Then, letting $\delta-(r-u)$ and letting $\alpha_{i}=1-(1-\gamma) p_{i}(l)$, worker $\mathrm{i}$ quits if and only if

$$
\int_{0}^{65-a_{i}+\hat{\beta} F} \alpha_{i} e^{-\delta t}\left[V_{i}(0)-S_{i}(0)\right] d t>M_{i}
$$

To obtain an estimable quit equation from (4), assume: 


$$
\alpha V(0)=X_{1} \beta_{1}
$$

$$
\alpha S(0)=X_{2} \beta_{2}
$$

$$
M=X_{3} \beta_{3}
$$

Denoting $\frac{\left(e^{\hat{n}(65-a+\dot{\beta} F)}-1\right.}{\delta}$ by $g(a, \delta, \hat{\beta} F)$, and substituting (5) $-(7)$ into (4).

$$
Q=\left\{\begin{array}{l}
1 \text { if } g(a, \delta, \hat{\beta} F)\left[X_{1} \beta_{1}-X_{2} \beta_{2}\right]-X_{3} \beta_{3}>0 \\
0 \text { otherwise }
\end{array}\right.
$$

Clearly, the net gain from changing jobs. the left hand side of (8), will be measured with error. We assume this error term, denoted $\mu_{Q}$. is distributed normally with zero mean and is i.i.d. Therefore, the quit equation we estimate is

$$
Q=\left\{\begin{array}{l}
1 \text { if } g(a, \delta, \hat{\beta} F)\left[X_{1} \beta_{1}-X_{2} \beta_{2}\right]-X_{3} \beta_{3}>\mu_{Q} \\
0 \text { otherwise }
\end{array}\right.
$$

The worker characteristics that we measured and that affect alternative opportunities include education, race. sex, age. geographic location, dexterity, as measured by scores on the physical dexterity test. and employment status when hired ( a worker who was on a temporary lay-off from a desirable previous job might be likely to quit when recalled from the layoff).$^{16}$ Each of the factors affecting alternative opportunities could also affect job satisfaction $X_{2}$, thus the sign of those variables is indeterminant. However, we would expect workers that were employed at the time of application to have a significantly higher

16. One might argue that employers should be concerned with the total effect of education on the probability of a worker quitting taking into account the better alternative opportunities available to the better educated workers. However, we are concerned with explaining wage differences in the market. not at the firm being studied, where there are no wage differences due to educalion differences. In the market equilibrium better educated workers have higher wages. There is no evidence that the gain for a job change is positively correlated with education. Hence. alternative opportunities have the same attraction for all workers but better educated workers have lower quit propensities. It is this difference in quit propensities, not of the effect of alternative opportunities, which contributes 10 differences in the equilibrium wage at different education levels. 
level of job satisfaction (one reason they left the previous job was the anticipation of increased job satisfaction) and hence to be less likely to quit. There are also job related characteristics such as job complexity that affect job satisfaction but not alternative opportunities.

Finally we would expect stick-to-itiveness (as measured by years of education and high school graduation), and whether the worker is married to independently impose additional mobility costs. Those variables are not multiplied by $g(a, \delta, \beta F)$. They enter directly into the quit equation as elements of $X_{3}{ }^{17}$

As can be seen in Table 3a our major hypothesis is confirmed. H.S. graduation has a strong negative effect on the probability of a worker quitting. This effect is independent of the direct effect of schooling. We can reject the hypothesis that the only reason better educated individuals have lower quit propensities is that they learned not to quit in school.

Equation (9) was estimated by the method of maximum likelihood, using a pooled sample from the southern and midwestern locations. Individuals were omitted if they were laid-off before being with the firm for six months and selection bias was avoided by also omitting workers in the same hiring cohort that would have been laid-off before six month had they not already quit. (All layoffs were made strictly by seniority). Because the likelihood function is almost flat with respect to changes in $\delta$ offset by compensating changes in the vector of variables multiplied by $\delta$, the standard errors of $\delta$ and of the coefficients of variables multiplied by $g(a, \delta, \hat{\beta} F)$ are high. Although statistically insignificant, they have values consistent with the model. Individuals such as white males that have better alternative opportunities are more likely to quit these jobs; workers who

17. See Mincer (1978) for an analysis of the effect of marital status on worker mobility. 
were employed when they applied for these jobs are less likely to quit. Similar confirmation was provided by the negative value of $\hat{\beta}$. Our estimates suggest that females in our sample anticipate spending 7 fewer years in the labor force than do males. This finding is consistent with unpublished research by Jacob Mincer. Using the PSID sample Mincer finds that women spend roughly $25 \%$ less time in the labor force than men. Finally the similarity in the " $t$ " statistics obtained using the gradient, hessian and White methods suggests that the model is not grossly misspecified.

To obtain more precise estimates of $\beta_{1}$ and $\beta_{2}$, and to make use of Mincer's findings on the shorter work-life of women, we reformulated equation (9) as

$(9 a)$

$$
Q= \begin{cases}1 & \text { if } h(a, \delta . \hat{\gamma} F)\left(X_{1} \beta_{1}-X_{2} \beta_{2}\right]-X_{3} \beta_{3}>\mu_{Q} \\ 0 & \text { otherwise }\end{cases}
$$

where $h(a . \delta . \hat{\gamma} F)=\frac{e^{-.05(1-.25 F)(65-\mathrm{agc})}-1}{-.05}$

That is, we impose the restrictions that $r-\mu=.05$ and that the effective work-life of women is $25 \%$ shorter than that of men.

Equation (9a) was estimated using a probit estimation procedure. The estimated coefficients. and the effect of a change in each independent variable on the probability of a worker quitting are presented in Table $3 \mathrm{~B}$.

Insert Tables $3 \mathrm{~A}$ and $3 \mathrm{~B}$ about here

If job complexity and match are included as independent variables, when (9a) is estimated the sample size falls to 1532 and the absolute value of all the " $t$ " statistics also falls. However. none of the results shown in Table 3B are significantly affected: high 
school graduation is estimated to correspond to a reduction in the probability of the worker quitting of -.052 at a $10 \%$ quit probability and -.083 at a $20 \%$ quit probability. Similarly if quit propensity is estimated separately for men and women in our sample, the effects noted in Table 3B hold for each subsample.

We checked the finding that high school graduation significantly affects quit propensities using the 1968-1982 PSID sample. We estimate that each year of postprimary education has a statistically and economically insignificant effect on a worker's quit rate, while completion of high school is associated with a reduction in the individual's quit rate of roughly one-third.

Insert Table 4 about here

When tenure was not included in a standard earnings equation using the 1981 PSID data set, the effect of high school graduation on the logarithm of wages is more than 3 times as large as the effect of completion of either 11 th or 13 th grade. If tenure effects are included as a right hand variables, the impact of high school graduation on wages falls by $40 \%$. Thus, to a considerable extent, the higher earnings of high school graduates are due to rewards to their longer tenure, or their expected tenure. Even after correcting for tenure, completion of 11 th grade or 13 th grade increases earnings by approximately $4.7 \%$, while graduation from high school increases earnings by approximately $11 \%$ (This coefficient was not statistically significant: a not surprising result given the cubic specification of the education function, as well as the permitted discontinuities at H.S. graduation and college graduation, and the scarceness of observations outside of 10 to 16 years of schooling. The cubic specification makes it unlikely that estimates of the effect of high school graduation on earnings are capturing higher moments of the relationship 
between schooling and learning. Omitting the cubic term increases the " $t$ " statistics for all the other education variables.

Insert Table 5 about here

\subsection{Absenteeism Model}

We first present a theoretical model that shows why differences in expected absenteeism rates can significantly affect the wages of workers. We then estimate the discontinuities in expected absenteeism rates associated with H.S. graduation for workers in our sample. In evaluating the cost of absenteeism to firms. the nature of the production process is critical. Traditional economic analyses of absenteeism assume a worker's marginal product is equal to his wage and the cost of absenteeism is the wage of the worker. In this section we consider the opposite polar case where the production process requires $k$ workers to operate. If more than $k$ workers are present, the extra workers are redundant, they do not increase outpul. If fewer than $k$ workers appear, output is zero. To simplify the notation, we assume output is linear in the number of workers, and normalize the value of output to be equal to $\dot{k}$. The number of workers hired is denoted by $n$, the wage of each worker by $\omega$, the probability that a worker appears for work by $p$, and the expected profit of a firm employing $n$ workers by $\pi(n)$. We let $P\left(S_{n} \geqslant k\right)$ denote the probability that at least $k$ workers are present when $n$ workers are hired. Finally, we assume that workers are not paid if they are absent (this assumption is made so that we can focus on the indirect costs of absenteeism, rather than the direct cost of paying for a worker).

$$
\pi(n)=\bar{k} P\left(S_{n} \geqslant k\right)-n p \omega
$$

The expected marginal product of the $n+1$ worker is 


$$
\tilde{k}\left[P\left(S_{n+1} \geqslant k\right)-P\left(S_{n} \geqslant k\right)\right] \text {. }
$$

The net expected value of the marginal worker is

$$
\begin{aligned}
\pi(n+1)-\pi(n) & =\tilde{k} P\left(S_{n+1} \geqslant k\right)-(n+1) p \omega-\bar{k} P\left(S_{n} \geqslant k\right)+n p \omega, \\
& =p \tilde{k} P\left(S_{n} \geqslant k-1\right)+(1-p) \tilde{k} P\left(S_{n} \geqslant k\right)-\tilde{k} P\left(S_{n} \geqslant k\right)-p \omega, \\
& =p \tilde{k}\left[P\left(S_{n} \geqslant k-1\right)-P\left(S_{n} \geqslant k\right)\right]-p \omega . \\
& =p\left[\tilde{k} P\left(S_{n}=k-1\right)-\omega\right] .
\end{aligned}
$$

The expected value of the marginal worker is the probability that worker is decisive (enables the plant to operate) times the value of the production process, minus that worker's expected cost to the firm.

A firm increases the number of workers it employs so long as (10) is positive; it chooses the smallest $n$ such that

$$
p \tilde{k} \frac{n !}{(n-j) ! j !} p^{j}(1-p)^{n-i}-p_{\omega}<0, \text { where } j=k-1
$$

If we consider the case where workers are paid even if they are absent. the usual policy in U.S. firms for routine levels of absenteeism, (10) is rewritten as

$$
\tilde{p} \tilde{k}\left(S_{n}=k-1\right)-\omega
$$

and (11) as

$$
p \tilde{k} \frac{n !}{(n-j) ! j !} p^{i}(1-p)^{n-j}-\mu<0
$$

In Appendix A we present an example showing the effect of changes in (1-p). the probability of a worker being absent, on the profitability of the firm. As that example illustrates, even if firms do not pay workers when they are absent, a given change in the probability of a worker being present can have a more than proportional effect on the equilibrium wage of the worker. Consequently traits that are correlated with low 
absenteeism rate, may be significantly rewarded in the labor market.

In estimating the determinants of absenteeism we assume that a worker is more likely to be absent the higher is his level of job dissatisfaction, and the lower his diligence. As in the quit equation, job satisfaction is measured by the elements of $X_{2}$. We use education and high school graduation as proxies for diligence-an individual who had insufficient diligence or persistence to complete high school is likely to have poorer than expected attendance habits. We shall assume that absenteeism (both days and occasions of absenteeism as a percentage of possible days worked) is a linear function of $\boldsymbol{X}_{\mathbf{Z}}$. our proxies for diligence. and a normally distributed error term.

In the quit equation we were able to separate the effect of education on job satisfaction from its effect on stick-to-itiveness by arguing that job satisfaction has a greater effect on the quit rates of workers with longer expected future worklines. The education $\times g(a, \delta, \hat{\beta}, F)$ term captured the effect of education on quits that was caused by its effect on either alternative opportunities or job satisfaction. This option is not available to us in the absenteeism equations: we assume workers are trading off one period gains and loses from absences. Consequently. the estimated coefficients on education and high school graduation could be estimating the effect of lower (or higher) levels of job satisfaction of better educated workers on their absence rates. The results from the previously estimated quit equations suggest this is not happening.

As mentioned, two measures of absenteeism are used as dependent variables.

Percentage of days absent is estimated using a Tobit procedure. Here, we are implicitly assuming that discrete absenteeism data can be approximated by a continuous distribution, and that the error term in the estimation equation is normally distributed but truncated so that absenteeism rates that the model predicts would be negative are recorded as zeros. 
We calculated the percentage of days workers were absent during their first six months on the job; however, because not all the workers in our sample completed 6 months of work those observations were weighted by the square root of the number of days for which they were observed.

Insert Table 6 about here

We also used occasions of absent as a dependent variable. In those calculations we restricted ourselves to individuals who worked for 6 months, and used the negative binomial procedure described by Hausman, Griliches and Hall (HGH).

The implicit assumptions made by using the negative binomial model are that incidents of absenteeism (several consecutive days absent are recorded as one incident) are generated from a binomial distribution which, because of the large number of observations for each individual, can be approximated by a Poisson arrival process; and that the $\lambda$ parameter which describes the Poisson process has gamma distribution across the population. HGH describe a maximum likelihood procedure to compute the effect of various independent variables on $\lambda$. (Because the probability of being absent is a function of whether the worker was absent on the previous day, the independence assumption required by the binomial distribution is inappropriate for modeling percentage of days absent. It seems more reasonable to expect incidents of absenteeism to be independently distributed.)

Insert Table 7 about here

Whether days or occasions are used as a measure of absenteeism we find that high school graduation has a negative effect on absenteeism. This effect is statistically 
significant regardless of the estimation procedure used. On the other hand education has a positive. albeit statistically insignificant effect, on absenteeism. Thus, it seems unlikely that high school graduates learned in secondary school the traits that gave them low rates of absenteeism. Instead, the same unobserved characteristics that lead to successful completion of high school seem to lead to low rates of absenteeism.

\subsection{Output Per Hour}

The final indicator of performance explored was the logarithm of normalized output per hour during the w'orker's first month at the plant. As previously noted. newly hired workers are randomly assigned to jobs and paid piece-rate. We assume that output per hour is a linear function of all our observed characteristics, including the match term described above.

In Table 8 the OLS regression coefficients for this performance measure are reproduced for each location with " $t$ " statistics beneath them.

Insert Table 8 about here

From Table 8 we see that matching better educated people to more complex jobs has a trivial effect on performance. This finding suggests that the pecuniary reward to education for the workers in the sample is not due to skills learned in school that help those workers learn complex production tasks. In Table 2 we computed the effect of education on the logarithm of normalized previous pay for workers in Plant A. Our best estimate was that each year of secondary education had a $4-5 \%$ effect on the pay of the workers in our sample. On the other hand, restricting the sample to workers in that plant we find that each year of education has only a $1.3 \%$ effect on the output of workers in that plant. This 
effect w'as not statistically significant.

Thus to the extent that the same characteristics that affect a workers output, ability to perform complex jobs, absenteeism, and quit propensity on their current job had a similar effects on performance on previous jobs (where there are significant pay differences by education), the data suggest that pay differences among the workers in our sample that are attributable to education are, in large part, due to factors such as a lower propensity to be absent or to quit. and not exclusively due to differences in expected output per hour or the ability of the better educated workers to learn more complex manufacturing jobs. Of course, these pay differences may be due to the ability of better educated workers to qualify for more complex non-manufacturing jobs, or for their performance to be higher in non-manufacturing jobs. On the other hand, for many of the jobs in the service sector it seems unlikely that skills learned in secondary school affect output. The implicit assumption we are making is that the effect of education on productivity, and on the ability to perform complex tasks, for the jobs encompassed by our data is similar to its effect on the previous jobs of the workers in our sample. Figure 2 describes the distribution of jobs in our sample according to the number of weeks required to learn each job.

Insert Figure 2 about here

Although one should be extremely cautious about generalizing these results beyond our sample of semi-skilled production workers, the PSID data provides an indirect means of gathering evidence of the impact of a low quit propensity on the wage premium received by high school graduates. 


\subsection{Magnitude of Effects}

There is considerable evidence that during business slumps firms hoard workers: pay wages above the value of the product of the workers. Implicit contract theory maintains that these high levels of wages and employment are consequences of optimal risk sharing between firms and workers. Consequently during severe business slumps we would expect firms to benefit from (or be hurt less by) quits and unpaid absences. Consequently, to obtain quantitative estimates of the effect of the low quit propensity and low absenteeism of high school graduates on their wages, we interacted county unemployment rates with high school graduation while estimating a wage equation for males workers in the PSID data set between 1968 and 1981. As in Tables 4 and 5 we included education, education squared, and education cubed as independent variables to reduce the possible role of high school graduation in approximating a precluded degree of curvature in the relationship between a dependent variable and education.

Insert Table 9 about here

We estimate that, if the county unemploymeni rate is zero, graduation from high school has roughly 3 times as great an effect on wages as does completion of 11 th grade. While, if the county unemployment rate is over $12 \%$, the wage premium received by high school graduates disappears.

This pro-cyclical behavior of the wage premium for completion of high school is especially surprising given the occupational distributions of high school dropouts and high school graduates. High school dropouts are over represented among blue collar workers ( $54 \%$ of the blue collar workers in the PSID sample were high school dropouts, while only $10 \%$ of the white collar workers were high school dropouts). Raisian finds that the wages 
of blue collar workers relative to those of white collar workers are procyclical. ${ }^{18}$ Hence the different occupations chosen by high school graduates and high school dropouts would cause the wage premium for high school graduation to behave counter-cyclically.

We also found a general procyclical effect of unemployment on wages-however, that relationship was sensitive to the particular specification chosen. When logarithms of the unemployment rates are used as independent variables the coefficient of the logarithm of the national unemployment rate is statistically insignificant, while the coefficient of the logarithm of the county unemployment rate minus the logarithm of the national unemployment rate is positive and statistically significant. This variable was introduced to allow for the possibility. suggested by Hall, that areas of the county that have high unemployment rates pay high wages. ${ }^{19}$

\section{SAMPLE SELECTION BIAS}

As we discussed above, we have strong reasons for believing that sample selection bias is not a serious problem for our sample. However, to the extent sample selection is a problem. the biases introduced prejudice the analysis against the results we obtained. Hence our results are stronger than would be indicated from the estimated coefficients and "1" statistics.

Since only a trivial number of applicants were rejected for reasons other than low scores on the dexterity test, we shall restrict the discussion in this section to the biases

18. We used the same classification scheme as Raisian in determining which 2 digit occupations were blue collar and which were white collar.

19. Note that the formulation we have chosen has the form $\ln w_{n}^{\prime}-X_{i r} \beta+\eta_{n}$ where $\eta_{1 r}-N\left(0 . \sigma^{2}\right)$. Coleman has argued against assuming that $\eta_{n}$ is distributed $i . j . d$. if one wishes to study cyclical effects. He argues that a more reasonable model is $\ln w_{4}=X_{i 1} \beta+\eta_{11}+\epsilon_{1}$, which allows for cyclical effects in the error term, and a GLS estimation procedure. Consequently, the " $t$ " statistics for our OLS estimates of the cyclical variables should be viewed with caution. 
introduced from the application decision of workers.

Imagine an unobserved application equation. A worker applies for a job with this firm if and only if

$$
X \gamma>\epsilon_{1}
$$

Having applied and been accepted at this job, the worker subsequently quits if and only if

$$
X_{1} \beta_{1}>\epsilon_{2} \mid\left(X \gamma>\epsilon_{1}\right)
$$

and is absent if and only if

$$
X_{2} \beta_{2}>\epsilon_{3} \mid\left(X \gamma>\epsilon_{1}\right)
$$

Because better educated workers had higher wages on their previous jobs and better alternative opportunities, we would expect the coefficient on education in (12) to be negative. Since (12) is not observed. $\epsilon_{1}$ and education are negatively correlated. We expect that. at least for employed applicants, $\epsilon_{1}$ is positively correlated with $\epsilon_{2}$ and $\epsilon_{3}$. A worker who was easily induced to leave his previous job is likely to be easily induced to leave his current job. This low level of commitment to his job might also be expected to lead to a higher than expected probability of being absent. Therefore, we expect $\epsilon_{2}$ and $\epsilon_{3}$ to be negatively correlated with education in equations (13) and (14). Hence, sample selection causes an upward bias on the estimated coefficients on education and H.S. graduation in the quit and absenteeism equations, leading to an underestimate of the magnitude of the negative correlation between H.S. graduation and the propensity to be absent or to quit. Because most firms pay higher wages to better educated workers, they are not subject to this form of sample selection bias. In the market equilibrium it is the unbiased correlation between education and performance that determines the rate of return to education. Thus we have underestimated the effect of the negative correlation between H.S. graduation and absenteeism and quit propensity on the correlation between earnings 
and H.S. graduation.

\section{COMPARISON WITH PREVIOUS STUDIES}

\subsection{Quit Rates}

Previous estimates of the effect of education on quit propensity have varied widely. However, with the exception of recent work by Flinn, Miller, and Mincer and Jovanovic, those studies treated tenure as an independent variable without correcting for worker heterogeneity and hence suffered from serious simultaneous equation biases. ${ }^{20}$

To see the source of that bias, imagine an unobserved tenure equation

$$
\text { tenure }=f(X)+\eta_{1}
$$

as well as an estimated quit equation,

$$
\text { Quit }=\left\{\begin{array}{l}
1 \text { if } X \beta_{1}+\left(\text { tenure } \beta_{2}>\eta_{2}\right. \\
0 \text { otherwise }
\end{array}\right.
$$

By including tenure in the quit equation, (16) is holding tenure constant when estimating the effect of the components of $X$ on quit probabilities. If a particular element of $X$ (such as education) had a negative effect on quit propensity it would have a positive effect on tenure. Holding tenure fixed forces education to be negatively correlated with $\eta_{1}$. Since $\eta_{1}$ and $\eta_{2}$ are positively correlated-individuals who for unobserved reasons have more tenure than expected are likely to have lower than expected quit propensitieseducation is negatively correlated with $\eta_{2}$. Consequently, the estimated coefficient for

20. The papers by Flinn and Miller do not direcily address the question of the effect of education on quil propensity; however in private conversalions they confirmed that their unseported results were consistenl with the results in this paper. The Mincer and Jovanovic paper partially corrected for worker heterogeneity by including previous mobility as an independent variable in the quit equation they estimated. They found that with this corfection education was negatively correlated with quit ñiopensity. 
education in Equation (16) is biased upward. This bias could cause the estimated correlation between education and quit propensity to be positive even if the true relationship is negative.

One might argue that it is the biased not the unbiased coefficient on education that should concern us. That is, suppose a wage equation is estimated with tenure included as an independent variable. If education is affecting wages through its effect on quit propensity, the biased coefficient from the quit equation on education partially explains why people with the same tenure levels, but different education levels, receive different wages.

A wage equation that includes tenure as an independent variable does not. however. explain why earnings of better educated workers rise more rapidly with tenure than do the earnings of less well educated workers. One possible explanation is that employers perceive that better educated workers have lower quit propensities than do less well educated workers. Firms invest more resources in training better educated workers since the low quit propensities of those workers enable firms to recapture their investments in human capital. These differences in post-schooling training would result in steeper wage-tenure profiles for better educated workers. Consequently, schooling, by providing a signal of quit propensity, would be rewarded in the short-term by greater training, and in the long-run by higher life-time earnings. This argument does not preclude a social return from the signaling aspects of education-directing firm specific training to workers with low quit propensities results in efficiency gains.

\subsection{Credentialism}

We have argued that the negative correlation between high school graduation and both quit propensity and absenteeism gives some a support for a sorting explanation for the positive correlation between education and earnings. There are several potential problems 
with using this line of reasoning. First. the literature revieu by R. Layard and G. Psacharapoulos "The Screening Hypothesis and Returns to Education" seems to suggest that the effect of education on earnings is not significantly greater for completion of high school or college than for other years of education. However, there is considerable evidence that the rate of return to education is greatest in primary school (perhaps because persistence as reflected in a low' quit propensity and low absenteeism is taught there) and lowest in post-secondary school (see George Psacharapoulos "Returns to Education: an Updated International Comparison"). Because a higher proportion of the education of high school dropouts is in primary school, we would expect their rates of return to education to be higher than the returns to high school graduates even if completion of 12 th grade has a much greater effect on earnings than does completion of 11 th or 10 h grade. In our sample, and in the PSID sample we find that completion of high school has a strong effect on earnings independent of the effect of education on earnings. ${ }^{21}$

Another possible reason for the wide range of estimates of the effect of high school graduation on wages or earnings is that previous studies did not allow for the effect of the unemployment rate on the premium for high school graduation. As we observed in Table 9 a high unemployment rate would wipe out the wage premium received by high school graduates. Hence, studies of the effect of high school graduation on earnings are sensitive to the relevant unemployment rate for their samples.

21. As discussed above. we estimate that for white males in the PSID sample completion of 1/th or 13th grade increases wages by roughly $4.7 \%$ while high school graduation increases wages by $14.9 \%$. Similarly we estimated that completion of 15 th grade increases wages by only $5.9 \%$ while compieting 16 th grade (graduation from college) increases wages by $14.4 \%$. Similarly Olsen. White and Shefrin found that. after correcting for risk. the pecuniary benefits of post-secondary education only outweigh the costs if the individual graduates from college. In a private conversation Shefrin reported that they also found the same result for secondary education and high school graduation. 


\subsection{Absenteeism}

A second potential criticism of our proposed investigation is that absenteeism and quit propensity are not important aspects of the productivity of workers. This claim was made about absenteeism by Steven Allen in "How Much Does Absenteeism Cost". The productivity equation Allen estimates is extremely sensitive to his model specification. He treats labor, absenteeism and the capital/labor ratio as independent variables in a CobbDouglas production function estimating output per worker. However, firms with low absenteeism rates choose high capital-labor $(K / L)$ ratios: the negative effect of absenteeism on output is greater the higher is the $K / L$ ratio (alternatively firms whose technology dictates high $K / L$ ratios will choose wage schedules and hiring criteria which result in low absenteeism rates). Similarly, firms with high absenteeism rates employ more workers to ensure adequate replacements in case of excessive absenteeism. The $K / L$ ratio, labor and absenteeism should all be treated as endogenous variables. This is not a problem for our analysis. We did not estimate the effect of absenteeism on productivity. We showed which worker characteristics were correlated with absenteeism and simulated, in Appendix A. the possible impact of differences in absenteeism on the market wage of workers.

To see the importance of Allen's specification on his results. suppose the only cost of absenteeism is overmanning as reflected in a lower capital-labor ratio. Then. output per hour could either be specified as a function $h(\cdot)$ of both the capital-labor ratio and the absenteeism rate for the firm or as a function $g(\cdot)$ of the capital-labor ratio. If $g(\cdot)$ is a geometric function while $h(\cdot)$ is significantly different from the product of two geometric functions, then Allen's econometric specification would have all the costs of absenteeism being captured by the capital-labor ratio. 
In an earlier paper Allen (1981) estimated determinant of absenteeism. In that paper after correcting for wage differences he found that education does rot have a statistically significanı effect on absenteeism and the effect of wages on absenteeism is small. but statistically significant. However if absenteeism directly effects wages-so that to the extent that better educated workers are less likely to be absent they are paid more-then Allen may be measuring an extra-ordinarily large response of wages to absenteeism, as well as a significant relationship between education and absenteeism.

\subsection{Signaling}

There have been several previous empirical studies of the possible signaling effects of education on earnings. In particular John Riley [1979] and Kenneth Wolpin [1977] have each used data on the relative incomes of self employed workers and employees of firms to support a signaling explanation for the correlation between education and earnings. The results in this paper are consistent with their findings in support of signaling theory: However, their results would also be generated by a pure human capital model with unobserved heterogeneity across workers and random shocks affecting school leaving dates. In that scenario the most able workers at any education level choose jobs where productivity is directly rewarded. Consequently, as Riley and Wolpin find, earnings would be higher in those occupations. (See Weiss [1980] for a non-signaling model in which earnings are systematically higher for the self-employed.)

\section{REVIEW OF RESULTS}

Recent large sample studies have shown returns to education in the region of $5 \%$. We find a similar rate of return for the pay on their previous job for workers in our sample. A large component of this rate of return is the discontinuous increase in wages associated with high school graduation. 
Presumably the higher earnings of high school graduates are due to their higher productivity relative to high school dropouts. We investigated four components of productivity: output per hour, comparative advantage on more complex task, propensity to quit, and propensity to be absent. We found that high school graduation appeared to be uncorrelated with output per hour, and high school graduates did not appear to have a comparative advantage on more complex jobs. On the other hand, high school graduates were significantly less likely to quit or to be absent.

We also found that the significant wage premium received by high school graduates in the PSID sample is pro-cyclical. We estimated that when the county unemployment rate reaches $12 \%$ this wage premium vanishes. Consequently, if a low quit propensity and a low rate of absenteeism, are valued more during booms than slumps this data provides further support to the argument that a considerable portion of the estimated return to high school graduation is due to the sorting effect of that credential.

Of course, one should be cautious in generalizing from this study to the economy as a whole. In some occupations skills learned in secondary school clearly have a major effect on productivity. For our sample it seems that those unobserved attributes that lead some individuals to go to school longer than others. play a significant role in explaining the higher earnings of better educated workers. 


\section{REFERENCES}

Allen. Steven. "An Empirical Model of Work Attendance," Review of Economics and Statistics. Vol. 63, No. 1 (February 1981): 77-87.

Allen, Steven. "How Much Does Absenteeism Cost," Journal of Human Resources, 43 (Summer 1983): 379-393.

Bloom, David and Mark Killingsworth. "Correcting for Truncation Bias Caused by a Latent Truncation Variable, NBER Technical Working Paper No. 38, 1984.

Calvo, Guillermo. "Quasi-Walrasian Theories of Unemployment," American Economic Review, 69, No. 2, (May 1979): 102-107.

Calvo, Guillermo and Stan Wellisz. "Hierarchy, Ability and Income Distribution," Journal of Political Economy, 87, No. 5, (October 1979): 991-1010.

Coleman. Thomas. "Cyclical Variations in Individual Wages and Employment" unpublished mimeo, University of Chicago, 1984.

Fein, Mitchell. "Job Enrichment Does Not Work," Atlanta Economic Review, 55, (November-December 1975).

Freeman, Smith. "Wage trends as Performance is Plays Productive Potential," The Bell Jo,urnal of Economics, 8, (Autumn 1977): 419-443.

Guasch, J. Luis and Andrew Weiss. "Wages As Sorting Mechanism in Markets with Imperfect Information: A Theory of Testing," Review of Economic Studies, 47, No. 3. (July 1980): 653-664.

"An Equilibrium Analysis of Wage-Productivity Gaps," Review: of Economic Studies, 49, (October 1982): 485-497.

Hackman. Richard. "On the Coming Demise of Job- Enrichment," Department of Administrative Sciences, Yale University, Technical Report, No. 9, December 1974.

Harris, Milton and Bengt Holmstrom. "A Theory of Wage Dynamics," Reviex of Economic Studies, XLIX (1982); 315-333.

Hausman, Jerry and Bronwyn Hall and Zvi Griliches. "Econometrics Models for Count Data with an Application to the Patents - R\&D Relationship, "Econometrica. 52 (July 1984): 909-938.

Heckman, James. "Sample Selection Bias as a Specification Error," Econometrica. 47. (1979); 73-92.

Heckman, James. "The Common Structure of Statistical Models of Truncation, Sample Selection, and Limited Dependent Variables and a Simple Estimator for Such Models," Annals of Economic and Social Measurement, 5 (1976); 475-492. 
Layard. R. and G. Psacharapoulos. "The Screening Hypothesis and Returns to Education." Journal of Political Economy, 82 (September/October 1954): 985-998.

Lazear, Edward. "Why Is There Mandatory Retirement," Journal of Political Econom!. 87. No. 6 (December 1979): 1261-1284.

Liu, Pak-Wai and Yue-Chim Wong. "Educational Screening by Certificates: An Empirical Test," Economic Inquiry, 20, (January 1982); 72-83.

Medoff, James and Katherine Abrahams. "Experience Performance and Earnings," Quarterly Journal of Economics, 95, No. 4 (December 1980): 703-736.

Mincer, Jacob and Boyan Jovanovic. "Labor Mobility and Wages," Studies in Labor Markets, Sherwin Rosen, editor, University of Chicago Press, 1981. pp. 21-64.

Mincer, Jacob. "Family Migration Decisions," Journal of Political Economy, 86, No. 5, (October 1978): 749-774.

Mirves, P. H. and E. E. Lawler. "Measuring the Financial Impact of Employee Attitudes," Journal of Applied Psychology', 62, (1977): 1-8.

Muthén, B. and K. G. Jöreskog. "Selectivity Problems in Quasi-experimental Data."

Nicholson, N. and C. A. Brown and J. K. Chadwick-Jones. "Absence from Work and Job Satisfaction," Journal of Applied Psychology'. Vol. 61 (December 1976) pp. 728737.

Olsen, Lawrence, Halbert White, and H. M. Shefrin. "Optimal Investment in Schooling When Incomes are Risky," Journal of Political Economy', 87, (June 1979): 522539.

Olsen, R. J. "Distributional Tests for Selectivity Bias and a More Robust Likelihood Estimator," International Economic Review, 23 (1982); 223-240.

Psacharapoulos, George. "Returns to Education: An Updated International Comparison," Comparative Education, 17, 1981: 321-341.

Riley, John. "Testing the Educational Screening Hypothesis" Journal of Political Economy, 87, No 5, Part 2 (October 1979) 5227-5252.

Salop. Steven and Joanne Salop. "Self Selection and Turnover in the Labor Market," Quarterly Journal of Economics, 90, No. 4 (November 1976): 629-49.

Stiglitz, Joseph. "Alternatives Theories of Wage Determination and Unemployment in L.D.C.'s: The Labor Turnover Model," Quarterly, Journal of Economics, 88 (May 1974): 194-227.

Taylor, Daniel. "Absence from Work Among Full-Time Employees." Monthly Labor Review, 104, (March 1981): 68-70.

Viscusi, Kip. "Sex Differences in Workers Quitting," Review of Economics and Statistics 
Vol. 62. No. 3 (August 1980) pp. 388-398.

Weiss. Andrew. "Job Queues and Layoffs in Labor Markets With Flexible Wages." Journal of Political Economy: 88, No. 3 (May 1980): 526-558.

Weiss. Andrew: "A Sorting-cum-Learning Model of Education," Journal of Political Economy: (June 1983): 420-442.

White, Hal. "Maximum Likelihood Estimation of Misspecified Models," Econometrica, 50, 1982: $1-25$.

Wolpin, Kenneth. "Education and Screening "American Economic Review," 67, (December 1977); 949-58. 
TABLE 1

Mean Value of the Relevant Variable

\begin{tabular}{|c|c|c|c|}
\hline & $\begin{array}{l}\text { Plant A } \\
\text { Midwest } \\
\text { Plant } \\
\end{array}$ & $\begin{array}{l}\text { Plant B } \\
\text { South } \\
\text { Plant } \\
\end{array}$ & $\begin{array}{c}\text { Plant C } \\
\text { Southwest } \\
\text { Plant } \\
\end{array}$ \\
\hline$\%$ White & .72 & .76 & $\mathbf{N A}$ \\
\hline$\%$ Black & .24 & .20 & NA \\
\hline Age & 24.6 & 25.3 & 26.7 \\
\hline Education & 12.1 & 12.2 & 11.9 \\
\hline $\begin{array}{l}\text { Employed at time of } \\
\text { application ( } 1 \text { if employed, } \\
0 \text { otherwise) }\end{array}$ & .64 & .29 & .38 \\
\hline \% Male & .57 & .19 & .41 \\
\hline \%arried & .43 & .48 & .42 \\
\hline $\begin{array}{l}\text { Previous work } \\
\text { experience (in years) }\end{array}$ & 3.54 & NA & NA \\
\hline Weeks to learn job & 7.5 & 5.1 & 11.7 \\
\hline Score on screws test & 22.6 & 21.3 & 24.0 \\
\hline Score on pins test & 22.4 & 23.5 & NA \\
\hline $1 \mathrm{st}$ month output & 111 & 63 & 105 \\
\hline \% days absent & 2.96 & 2.3 & 3.0 \\
\hline \% occasions absent & 1.2 & 1.1 & 1.12 \\
\hline $\begin{array}{l}\text { Quit rate in first } \\
\text { six months on job }\end{array}$ & $9.8 \%$ & $18.2 \%$ & $12.3 \%$ \\
\hline
\end{tabular}


TABLE 2

REGRESSION ESTIMATES COMPARING THE IMPACT OF VARIOLS VARIABLES ON LOG HOURLY EARNINGS IN 1979

\section{Current Population Survey Sample Versus Weiss Sample} (" $t^{\circ}$ statistics in parentheses)

\begin{tabular}{|c|c|c|c|}
\hline & $\begin{array}{c}\text { CPS } \\
\text { With Size } \\
\text { of Firm* } \\
\end{array}$ & $\begin{array}{c}\text { CPS } \\
\text { With } \\
\text { Unionization* } \\
\end{array}$ & $\begin{array}{c}\text { Midwest } \\
\text { Plant }\end{array}$ \\
\hline Non-White & $\begin{array}{r}.070 \\
(7.14)\end{array}$ & $\begin{array}{r}-.073 \\
(5.24)\end{array}$ & $\begin{array}{r}-.027 \\
(-1.52)\end{array}$ \\
\hline Female & $\begin{array}{r}.343 \\
(57.44)\end{array}$ & $\begin{array}{r}-.262 \\
(21.86)\end{array}$ & $\begin{array}{r}-.239 \\
(-14.17)\end{array}$ \\
\hline Education & $\begin{array}{r}.047 \\
(5.73)\end{array}$ & $\begin{array}{c}.045 \\
(3.46)\end{array}$ & $\begin{array}{r}.185 \\
(2.48)\end{array}$ \\
\hline$(\text { Education } / 10)^{2}$ & $\begin{array}{r}.084 \\
(2.98)\end{array}$ & $\begin{array}{r}.035 \\
(.69)\end{array}$ & $\begin{array}{r}-.570 \\
(-2.03)\end{array}$ \\
\hline Tenure & $\begin{array}{r}.021 \\
(10.60)\end{array}$ & $\begin{array}{r}.012 \\
(4.42)\end{array}$ & $\begin{array}{c}.027 \\
(.707)\end{array}$ \\
\hline$(\text { Tenure } / 10)^{2}$ & $\begin{array}{r}-.043 \\
(12.73)\end{array}$ & $\begin{array}{r}-.029 \\
(6.26)\end{array}$ & $\begin{array}{r}-.120 \\
(-1.70)\end{array}$ \\
\hline Age-Educ.-6 & $\begin{array}{r}.022 \\
(11.96)\end{array}$ & $\begin{array}{r}.014 \\
(4.88)\end{array}$ & $\begin{array}{r}.049 \\
(4.03)\end{array}$ \\
\hline$\left((\text { Age-Educ. } \cdot 61 / 10)^{2}\right.$ & $\begin{array}{r}.033 \\
(15.84)\end{array}$ & $\begin{array}{r}-.042 \\
(6.73)\end{array}$ & $\begin{array}{c}-0.60 \\
(.5 .45)\end{array}$ \\
\hline Educ. Times Tenure & $\begin{array}{r}.038 \\
(2.98)\end{array}$ & $\begin{array}{r}.062 \\
(5.25)\end{array}$ & $\begin{array}{l}.0006 \\
(.19)\end{array}$ \\
\hline Educ. Times (Age-Educ.-6) & $\begin{array}{r}-.069 \\
(6.31)\end{array}$ & $\begin{array}{r}-.039 \\
(3.89)\end{array}$ & $\begin{array}{r}-.002 \\
(2.30)\end{array}$ \\
\hline Married Dummy & yes & yes & yes \\
\hline Number of Observations & 18.551 & 18.551 & 1,251 \\
\hline$R^{2}$ & .436 & .524 & .207 \\
\hline
\end{tabular}

- CPS data also has dummy variables for SMSA. region, occupation. induss ry. and either fom size or union membership. whether or not the worker was employed part-time, and urionizntion of industry.

- Weiss data is from the only plant in this study for which wage data on the previous job is avaitable. The dependent variable is the logarith of the wage their most recent job divided by the mean wage in the economy at the time they held that job. of

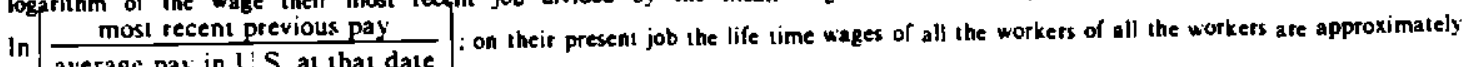
In averag identical. 
(The smaller $R^{2}$ s in columns 3 and 4 compared with columns 1 and 2 are due. in part. to less variance in earnings within the Heiss sample.)

Evaluating the effect of additional year of education. tenure and experience at the mean values in each sample for education. tenure and experience:

$\begin{array}{llll}\frac{\partial \ln \text { (wage) }}{\partial \text { educ. }} & .064 & .041 & .044 \\ \frac{\partial \ln \text { (w'age) }}{\partial \text { lenure }} & .016 & .012 & .031 \\ \frac{\partial \ln \text { (wage) }}{\partial \text { experience(proxy) }} & .0056 & .0040 & .061\end{array}$


TABLE 3A

\section{PROBABILITY OF QUITTING WITHIN FIRST SIX MONTHS ON THE JOB MAXIMLM LIKELIHOOD ESTIMATION PROCEDLRE}

\begin{tabular}{|c|c|c|c|c|}
\hline \multirow[b]{2}{*}{ Independent Variable* } & \multirow{2}{*}{$\begin{array}{c}\text { Estimated } \\
\text { Coefficient } \\
\text { or } \\
\text { Value } \\
\end{array}$} & \multicolumn{3}{|c|}{ 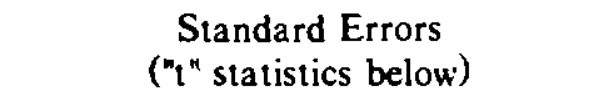 } \\
\hline & & $\begin{array}{l}\text { Gradient } \\
\text { Method }\end{array}$ & $\begin{array}{l}\text { Hessian } \\
\text { Method }\end{array}$ & $\begin{array}{l}\text { White's } \\
\text { Method }\end{array}$ \\
\hline$\delta$ & .26 & $\begin{array}{l}2.04 \\
(-.13)\end{array}$ & $\begin{array}{c}.61 \\
(-.42)\end{array}$ & $\begin{array}{l}.28 \\
(-.91)\end{array}$ \\
\hline $\begin{array}{l}\hat{3} \text { (effect of being female } \\
\text { on anticipated work-life) }\end{array}$ & -6.81 & $\begin{array}{l}42.3 \\
(-.16)\end{array}$ & $\begin{array}{l}10.6 \\
(-.63)\end{array}$ & $\begin{array}{c}4.19 \\
(-1.62)\end{array}$ \\
\hline H. S. Graduate & -.342 & $\begin{array}{r}.140 \\
(-2.44)\end{array}$ & $\underset{(-2.54)}{.135}$ & $\begin{array}{r}.136 \\
(-2.61)\end{array}$ \\
\hline College Graduate & -.242 & $\begin{array}{r}.367 \\
(-.66)\end{array}$ & $\begin{array}{l}.397 \\
(-.62)\end{array}$ & $\begin{array}{r}.444 \\
(-.59)\end{array}$ \\
\hline Education & -.07 & $\begin{array}{l}.171 \\
(-.44)\end{array}$ & $\begin{array}{r}.057 \\
(-.67)\end{array}$ & $\begin{array}{r}.035 \\
(-.76)\end{array}$ \\
\hline$g(a, \delta, \hat{\beta} F) \times$ education & .015 & $\begin{array}{l}.143 \\
(.11)\end{array}$ & $\begin{array}{l}.044 \\
(.34)\end{array}$ & $\begin{array}{l}.029 \\
(.53)\end{array}$ \\
\hline Married & -.091 & $\begin{array}{r}.078 \\
(-1.16)\end{array}$ & $\begin{array}{r}.077 \\
(-1.18)\end{array}$ & $\begin{array}{r}.077 \\
(-1.17)\end{array}$ \\
\hline $\begin{array}{l}g(a . \delta . \hat{\beta} F) \times \text { employed } \\
\text { at application }\end{array}$ & -.098 & $\begin{array}{r}.774 \\
(-.13)\end{array}$ & $\begin{array}{r}.231 \\
(-.43)\end{array}$ & $\begin{array}{r}.107 \\
(-.92)\end{array}$ \\
\hline Number of observations & 2146 & & & \\
\hline Log Likelihood & -741.99 & & & \\
\hline
\end{tabular}

Other independent variables included scores on each half of the dexterity test. race-location interactions, location effects, age and an intercept term. We used three different methods for calculating the standard errors because there is no consensus as to which is the correct technique. If the model is correctly specified. the three methods give the same asymptotic estimates. The estimates we obtain are sufficiently similar to provide some confidence that the model is not grossly misspecified. Computational costs precluded performing the model specification test suggested by White. If the model is misspecified then only the White standard errors have any economic content. 
TABLE 3B

\section{PROBABILITY OF QLITTING \\ WITHIX FIRST SIX MONTHS*}

\begin{tabular}{|c|c|c|c|c|}
\hline \multirow[t]{2}{*}{ Independent Variable } & \multirow[t]{2}{*}{ Coefficient } & \multirow[t]{2}{*}{$" r "$ statistic } & \multicolumn{2}{|c|}{$\begin{array}{l}\triangle \text { Quit Probability } \\
\text { from a } 1 \text { unit } \\
\text { change in the } \\
\text { Variable Evaluated at } \\
\text { Quit Probability of }\end{array}$} \\
\hline & & & $10 \%$ & $20 \%$ \\
\hline Intercept & -.922 & -1.54 & & \\
\hline H.S. Graduate &.,- 341 & -2.54 & -.059 & -.096 \\
\hline College Graduate & -.280 & -.72 & -.049 & -.078 \\
\hline Education & -.106 & -1.32 & -.019 & -.030 \\
\hline Married & -.097 & -1.26 & -.017 & -.027 \\
\hline$h(a . \dot{n} . \bar{F}) \times$ education & .0055 & 1.45 & .00097 & .0015 \\
\hline$h(a . \dot{0} . j F) \times$ agc & -.00029 & -.32 & -.000052 & -.000083 \\
\hline$h(a, \delta, \gamma F) \times$ male & .0012 & .16 & .00022 & .00034 \\
\hline$h(a . \dot{a} ; F) \times$ white $\times$ south & .068 & 4.58 & .012 & .019 \\
\hline$h(a . \delta . \gamma F) \times$ south & -.036 & -2.34 &. .0062 & -.0099 \\
\hline$h(a . \delta . \hat{\gamma} F) \times$ white $\times$ midwest & .0061 & 1.00 & .0011 & .0017 \\
\hline$h(a \cdot \delta . \hat{\jmath} F) \times$ employed at application & -.0023 & -4.95 & -.0040 & -.0064 \\
\hline $\begin{array}{l}h(a . \delta . j F) \times \text { pins section } \\
\text { of dexterity test }\end{array}$ & .00020 & .34 & .000035 & .000056 \\
\hline $\begin{array}{l}h(a . \delta . j F) \times \text { screws section } \\
\text { of dexterity test }\end{array}$ & .00094 & 1.94 & .00016 & .00026 \\
\hline Number of Observations & 2146 & & & \\
\hline$j$ set equal to -.25 , $\delta$ set equal to .05 . & & & & \\
\hline
\end{tabular}




\title{
TABLE 4
}

\section{QUITS PER YEAR FOR MALE PRIVATE SECTOR EMPLOYEES IN PSID SAMPLE 1968-82}

\author{
(" $\mathrm{t}^{\mathrm{H}}$ statistics in parentheses)
}

\section{Independent \\ Variable*}

H.S. graduate

Education

Education Squared

Education Cubed

Ln (Mean Experience

while in sample)

New Entrant

Non-white

Age

Mean Cty Unemp. minus

Mean Nat. Unemp

Mean Quits per year

Number of Observations
Coefficient

$(-2.26)$

.0030

(2.53)

$-.00011$

$(-2.76)$

$-.025$

(-3.67)

.014

(1.62)

$-.030$

$-.0023$

$(-5.30)$

.092

3781

.16

\# Each observation was weighted by the square root of the number of years the individual was in the sample.

- The other independent variables were 8 looations and two urban-suburban dummy variables, marital status. number of dependents, disabled, dummy variables for whether the individual has fewer than 2 years and fewer than 5 years of experience, as well as an intercept term. 


\section{TABLE 5}

\section{DEPE \DENT $I A R I A B L E:$ L. WAGES FOR 1981 PSID \\ SAMPLE OF WHITE MALES EMPLOYEES IX THE \\ PRIVATE SECTOR \\ ("t" statistics below coefficients)

$$
\begin{aligned}
& \text { Independent } \\
& \text { Variable* }
\end{aligned}
$$ \\ Coefficient}

Education

Education Squared

Education Cubed

H.S. Graduale

College Graduate

Number of Observations
$(2.57)$

$-.017$

$(-1.70)$

.00047

(1.47)

.1035

(2.03)

.075

(1.03)

1638

- The other in dependent variables were 8 locations and two urban-suburban durims variables. marital stitus. union membership. experience. experience squared. and experience cubed. $2:$ well as an intercept term. 
TABLE 6

\section{DAYS ABSENT AS A PERCENTAGE OF DAYS WORKED"}

Tobit Estimation Procedure

( $t$ statistics in parentheses)

\begin{tabular}{|c|c|}
\hline Independent Variable & Coefficient \\
\hline Intercept & $\begin{array}{c}7.38 \\
(2.54)\end{array}$ \\
\hline Male & $\begin{array}{r}.398 \\
(-.95)\end{array}$ \\
\hline Age & $\begin{array}{r}-.143 \\
(-5.89)\end{array}$ \\
\hline Education & $\begin{array}{l}.133 \\
(.58)\end{array}$ \\
\hline H.S. Graduate & $\begin{array}{l}-2.35 \\
(-4.04)\end{array}$ \\
\hline College Graduate & $\begin{array}{c}-1.34 \\
(-.69)\end{array}$ \\
\hline Married & $\begin{array}{l}-.046 \\
(.13)\end{array}$ \\
\hline Job Complexity & $\begin{array}{c}-.12 \\
(-.45)\end{array}$ \\
\hline Job Match & $\begin{array}{c}-.21 \\
(-1.10)\end{array}$ \\
\hline Employed at Application & $\begin{array}{c}-1.23 \\
(-3.56)\end{array}$ \\
\hline Number of Observations & 1890 \\
\hline Log Likelihood & -4781.2 \\
\hline
\end{tabular}

\# The data for Tables 6 and 7 come from all locations of the firm. rather than the two included in the quit equations.

* Each observation was weighted by the square root of the number of days worted. Dummy variables for the locations of the plants, the scores on the screws section of the dexterity test and race-location interactions at the two plants at which we had race data were also jucluded as independemt variable. 
TABLE 7

OCCASIONS ABSENT DURING THE
FIRST SIX MONTH ON THE JOB

Negative Binomial Model

( $t$ statistics in parentheses) ${ }^{\circ}$

Independent Variable*

Coefficient

Intercept

2.70

(5.68)

Male

$-.11$

$(-2.10)$

Age

$-.036$

$(-9.20)$

Education

(1.43)

H.S. Graduate

$-.239$

$(-2.59)$

College Graduate

$-.028$

(-.11)

Married

.0085

(.18)

Match

.011

(.35)

Job Complexity

$-.0011$

$(-.027)$

Employed at Application

$-.14$

$(-2.72)$

Number of Observations

1565

Log Likelihood

1333.5

\# Other independent variables were location. and score on the screws section of the dexterity test. and racelocation interactions for the two plants at which race data was available.

* Standard errors were calculated using the Hessian method. 
TABLE 8

NORMALIZED FIRST MONTH OUTPLT

Estimated by Ordinary Least Squares

(" $t$ " statistics in parentheses)

\begin{tabular}{|c|c|}
\hline Independent Variable & Coefficient \\
\hline Intercept & $\begin{array}{l}73.57 \\
(7.30)\end{array}$ \\
\hline Male & $\begin{array}{c}9.29 \\
(6.07)\end{array}$ \\
\hline Age & $\begin{array}{c}-.10 \\
(-1.08)\end{array}$ \\
\hline Education & $\begin{array}{c}1.35 \\
(1.61)\end{array}$ \\
\hline H.S. Graduate & $\begin{array}{c}-.21 \\
(-.08)\end{array}$ \\
\hline College Graduate & $\begin{array}{l}-12.61 \\
(-2,02)\end{array}$ \\
\hline Married & $\begin{array}{c}3.86 \\
(2.87)\end{array}$ \\
\hline $\begin{array}{l}\text { Score on } \\
\text { Dexterity Tesi }\end{array}$ & $\begin{array}{c}.25 \\
(1.75)\end{array}$ \\
\hline Match & $\begin{array}{l}.49 \\
(.59)\end{array}$ \\
\hline Job Complexity & $\begin{array}{c}5.83 \\
(5.51)\end{array}$ \\
\hline Employed at Application & $\begin{array}{l}1.13 \\
(.83)\end{array}$ \\
\hline Number of Observations & 1859 \\
\hline Multiple $R$-Square & .380 \\
\hline
\end{tabular}

- Other independent variables were location dummies. 


\section{TABLE 9}

\section{LOG OF NOMINAL WAGES\# \\ FOR MALE EMPLOYEES IN THE PRIVATE SECTOR*}

$$
\text { (" } \mathrm{t} \text { " statistics in Parentheses) }
$$

\begin{tabular}{|c|c|c|}
\hline Variable & \multicolumn{2}{|c|}{ Parameter Estimates } \\
\hline HS * County Unemp. Rate & $\begin{array}{l}-.0087 \\
(-3.61)\end{array}$ & $\begin{array}{l}-.0087 \\
(-3.61)\end{array}$ \\
\hline H.S. Graduation & $\begin{array}{r}.109 \\
(5.69)\end{array}$ & $\begin{array}{r}.111 \\
(5.81)\end{array}$ \\
\hline Intercept & $\begin{array}{c}3.25 \\
(7.01)\end{array}$ & $\begin{array}{c}3.15 \\
(6.78)\end{array}$ \\
\hline Education & $\begin{array}{r}.084 \\
(4.97)\end{array}$ & $\begin{array}{r}.084 \\
(5.01)\end{array}$ \\
\hline Education ${ }^{2}$ & $\begin{array}{c}-.0070 \\
(-3.78)\end{array}$ & $\begin{array}{l}-.0069 \\
(-3.77)\end{array}$ \\
\hline Education $^{3}$ & $\begin{array}{l}.00030 \\
(5.15)\end{array}$ & $\begin{array}{l}.00030 \\
(5.09)\end{array}$ \\
\hline Experience & $\begin{array}{r}.022 \\
(21.13)\end{array}$ & $\begin{array}{r}.023 \\
(21.53)\end{array}$ \\
\hline Experience $^{2}$ & $\begin{array}{l}-.00037 \\
(-14.50)\end{array}$ & $\begin{array}{l}-.00038 \\
(-14.84)\end{array}$ \\
\hline Disability & $\begin{array}{r}-.079 \\
(-7.54)\end{array}$ & $\begin{array}{r}-.086 \\
(-8.25)\end{array}$ \\
\hline Race & $\begin{array}{r}-.157 \\
(-22.93)\end{array}$ & $\begin{array}{r}-.158 \\
(-23.16)\end{array}$ \\
\hline Marital Status & $\begin{array}{r}.077 \\
(9.20)\end{array}$ & $\begin{array}{r}.082 \\
(9.80)\end{array}$ \\
\hline Time & $\begin{array}{r}.062 \\
(7.82)\end{array}$ & $\begin{array}{r}.060 \\
(7.59)\end{array}$ \\
\hline Union Membership & $\begin{array}{r}.191 \\
(30.58)\end{array}$ & $\begin{array}{r}.189 \\
(30.18)\end{array}$ \\
\hline Log CPI & $\begin{array}{r}.365 \\
(3.35)\end{array}$ & $\begin{array}{r}.386 \\
(3.54)\end{array}$ \\
\hline New Job & $\begin{array}{r}-.104 \\
(-13.71)\end{array}$ & $\begin{array}{r}-.118 \\
(-15.97)\end{array}$ \\
\hline $\begin{array}{l}\text { County Unemp. Rate minus } \\
\text { National Unemp. rate }\end{array}$ & $\begin{array}{l}.0014 \\
(.68)\end{array}$ & $\begin{array}{l}.0011 \\
(.55)\end{array}$ \\
\hline
\end{tabular}


National Linemp. Rate

Number of Observations

$R^{2}$

Part Time (worked

fewer than 1500 hours)
$-.0089$

$(-2.59)$

13612

.625

$-.077$

$(-8.06)$ 


\section{Appendix A}

To illustrate the effect of absenteeism on the equilibrium value of a worker to the firm let us consider a production process which requires 20 workers to operate, generates $\$ 10.000$ of income per day if it operates, and has a fixed cost of $\$ 5,000$ per day whether it operates or not. We shall assume workers are not paid if they are absent. In equilibritum, if the probability of a worker being absent is known by all employers and firms complete for workers so that wages are bid up to the level where each production process earns zero profits, we find that

$\begin{array}{ccc}\text { Probability of } & \begin{array}{c}\text { Profit Maximizing } \\ \text { Number of } \\ \text { Employees }\end{array} & \begin{array}{c}\text { Equilibrium } \\ \text { Daily Wage }\end{array} \\ .20 & 30 & 197.66 \\ .19 & 30 & 198.42 \\ .18 & 29 & 199.51 \\ .17 & 29 & 200.43 \\ .16 & 28 & 201.46 \\ .15 & 28 & 202.64 \\ .14 & 27 & 203.47 \\ .13 & 27 & 205.07 \\ .12 & 27 & 205.56 \\ .11 & 26 & 207.70 \\ .10 & 26 & 208.60 \\ .09 & 25 & 210.53 \\ .08 & 25 & 212.05 \\ .07 & 24 & 213.59 \\ .06 & 24 & 216.02 \\ .05 & 23 & 217.02 \\ .04 & 23 & 220.87 \\ .03 & 23 & 222.08 \\ .02 & 22 & 227.61 \\ .01 & 21 & 231.60 \\ .00 & 20 & 250.00\end{array}$




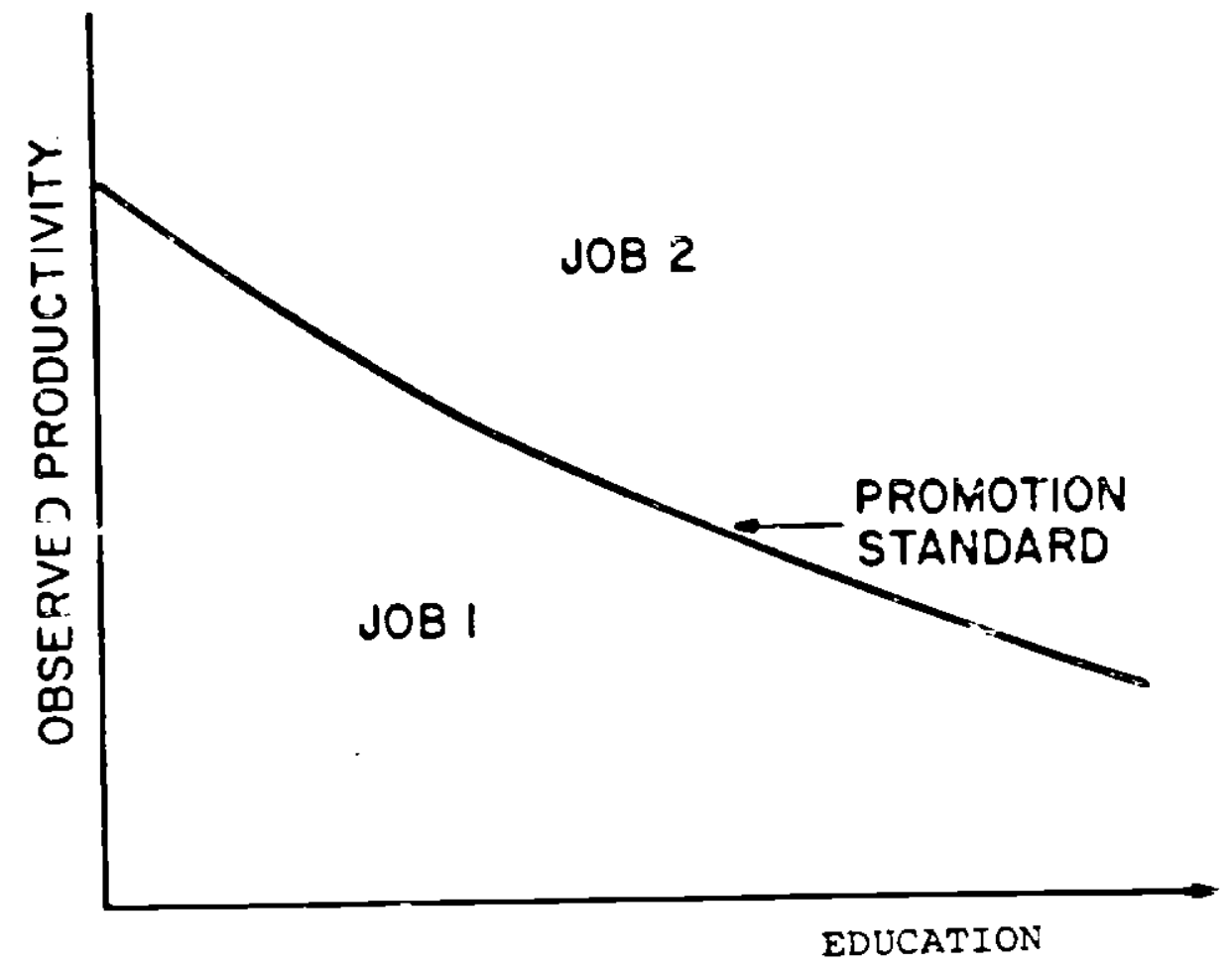

FIGURE 1 


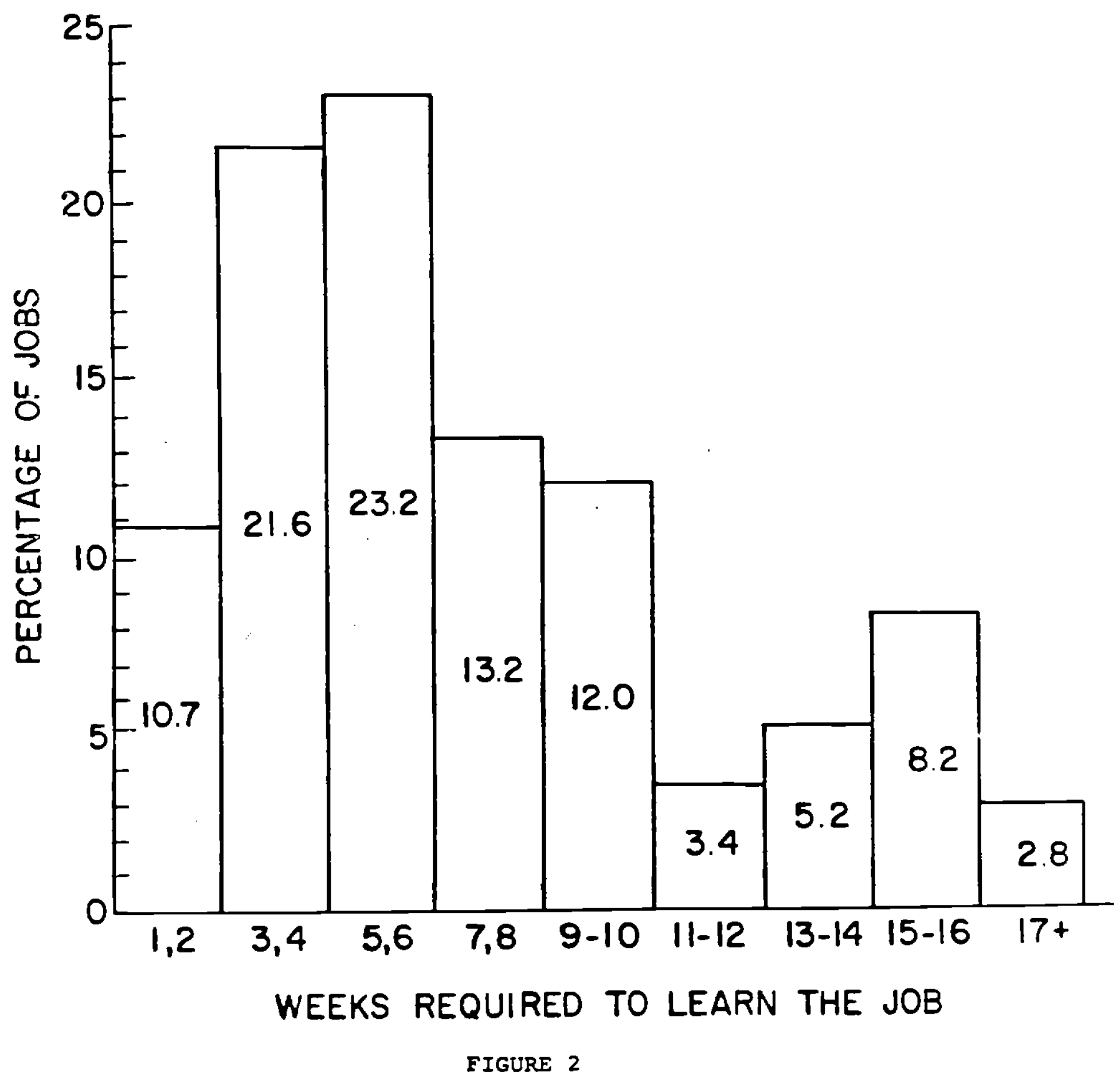

